\title{
Effects of Copper Content and Ni Activator on the Densification of W-Cu Composite via Infiltration Process
}

\author{
Ali Grinou ${ }^{1}$, Nabil Sadli ${ }^{2}$, Mounder Romane ${ }^{3}$, Aissa Toumi ${ }^{4}$ \\ ${ }^{1,2,3,4}$ Department of Research and Development, Laboratory of Materials Technology, Batna 05000, Algeria
}

\begin{abstract}
By using the infiltration method at a temperature of $1250^{\circ} \mathrm{C}$ and a holding time of $2 \mathrm{~h}$ in $\mathrm{H}_{2}$ atmosphere, W-Cu composites with different $\mathrm{Cu}$ content $(5,10,15,20,25$ and $30 \mathrm{Wt} \%)$ have been elaborated. In this study, a Tungsten porous substrate was prepared with cold uniaxial pressing. The results show that $25 \mathrm{Wt} \% \mathrm{Cu}$ is the maximum cupper content that can be infiltrated. In order to enhance the composites properties, Ni has been added as activator of W matrix. In this case, it was found that (W-5Wt\%Ni)-25Wt\% Cu gives the most interesting result in terms of density, hardness and microstructure.
\end{abstract}

Keywords: Tungsten, compacts, W-Cu-Ni composite, activator, Infiltration

\section{Introduction}

Due to their excellent electrical and mechanical properties, Copper-Tungsten $(\mathrm{Cu}-\mathrm{W})$ alloys have attracted a considerable degree of attention [1]. $\mathrm{Cu}-\mathrm{W}$ alloys are a pseudo-alloy of copper and tungsten. As copper and tungsten are not mutually soluble, the material is composed of distinct particles of one metal dispersed in a matrix of the other one [2]. The material combines the properties of both metals, resulting in a material that is heat-resistant, highly thermally and electrically conductive, and easy to machine [3].

Therefore $\mathrm{Cu}-\mathrm{W}$ alloys are widely used for a range of applications, such as: thermal management devices, electrodes, and electrical discharge machine [4-5]. Hence, these alloys are promising materials for manufacture of electrodes applications, which is the main objective of this research. Analyzing their characteristics, $\mathrm{Cu}-\mathrm{W}$ alloys present mutual insolubility or negligible solubility, $\mathrm{Cu}-\mathrm{W}$ compact powder shows very poor sinterability; even by liquid phase sintering above the melting point of the $\mathrm{Cu}$ phase [6-7]. The elaboration of a full density $\mathrm{Cu}-\mathrm{W}$ composite by mixing process is very difficult due to the big difference between melting points of tungsten (approximately $3400^{\circ} \mathrm{C}$ ) and copper (approximately $1083^{\circ} \mathrm{C}$ ); consequently there is no overlap of sintering temperature ranges [8]. Based on the lack of solubility between copper and tungsten, the infiltration process of copper liquid into the porous compact powder of tungsten is a possible approach for producing $\mathrm{Cu}$ $\mathrm{W}$ composite [9].

The infiltration of porous- compact tungsten by liquid copper is one of the most common methods for producing $\mathrm{Cu}-\mathrm{W}$ composite. However, this method presents some disadvantages such as: pores, copper lakes, and tungsten agglomeration [10-11]. To overcome these defects, nickel (Ni) was added to tungsten matrix as activator with different weight amount. The Nickel particles in a green specimen of compacted tungsten matrix improve the wetting and adhesion of copper-tungsten and facilitate nonporous composite production. This addition makes the desired uniform distributions copper-tungsten composite [12-13]. The main objective of this work is to study the effect of nickel (Ni) as an activator of tungsten matrix. Moreover, the homogenous distribution of liquid copper $(\mathrm{Cu})$ into porous tungsten compacts is achieved through the infiltration process. This last includes two steps: 1- preparation of porous green compact (W-Ni) by pressing the powders of tungsten with different weight percentage of nickel; 2- infiltration of melted copper into porous green compact of $\mathrm{W}-\mathrm{Ni}$ to form the (W-Ni)-Cu composites.

In this paper, the optimum weight percentage of infiltrated copper is examined. The effect of $\mathrm{Ni}$ as an activator on the microstructure/mechanical properties of the resulted alloy is also investigated.

\section{Experimental Procedure}

In the current study, powders of $\mathrm{W}$ (99\% purity with particle size $\leq 10 \mu \mathrm{m}), \mathrm{Cu}(98 \%$ purity with particle size $\leq 20 \mu \mathrm{m})$ and $\mathrm{Ni}(98 \%$ purity with particle size $\leq 10 \mu \mathrm{m})$ were used. Firstly, the effect of copper content on the elaboration of W$\mathrm{Cu}$ composites by infiltration process was investigated. For this purpose, the content of tungsten matrix (as substrate) was fixed and copper content was varied $(5,10,15,20,25$ and 30 Wt \%).

The percentage of copper was calculated in comparison to tungsten weight. Tungsten and copper compacts were separately cold pressed using uniaxial $(400 \mathrm{KN})$ hydraulic press. The infiltration was carried out in $\mathrm{H}_{2}$ atmosphere at $1250^{\circ} \mathrm{C}$ and $2 \mathrm{~h}$ holding time. Secondly, nickel was added to tungsten compacts with different rates $(1,2,3,4,5$ and $6 \mathrm{Wt}$ $\%$ ) to study its influence on the properties of the $\mathrm{W}-\mathrm{Cu}$ composites.

The elaborated $\mathrm{W}-\mathrm{Cu}$ and (W-Ni)-Cu composites were machined to remove the undesired solidified copper above the infiltrated samples. Then, their densities were measured using Archimedes' method. The theoretical densities of tungsten, copper and nickel are 19.3, 8.96 and $8.902 \mathrm{~g} / \mathrm{cm} 3$ 


\section{International Journal of Science and Research (IJSR) \\ ISSN (Online): 2319-7064}

Index Copernicus Value (2013): 6.14 | Impact Factor (2015): 6.391

respectively. The relative densities of the compacts were evaluated by dividing their measured densities on the theoretical ones. These measured densities were investigated using the instrument type voyager analytical balances proOHAUS. The hardness of the obtained compacts was measured using a Rockwell hardness tester (type OMAGAFFRI-250DRMS). Phase analyses of the different samples were conducted with X-ray diffractometer (XRD) (type Panalytical X'Pert Pro) with $\mathrm{Cu} \mathrm{K} \alpha$ radiation. Samples of the infiltrated $\mathrm{W}-\mathrm{Cu}$ and (W-Ni)-Cu composites were prepared for microstructural investigation. The resulted parts were seen under scanning electron microscopy SEM-EDX/ cartography micrographs (type SEI QUANTA 650).

\section{Results and Discussions}

\subsection{Effect of $\mathrm{Cu}$ content on relative sintered density and hardness of $\mathrm{W}-\mathrm{Cu}$ composites}

Figure 1 shows the effect of copper content on relative sintered density and hardness of $\mathrm{W}-\mathrm{Cu}$ composites, where the relative densities of infiltrated samples with different $\mathrm{Cu}$ contents were obtained by dividing their measured density on their theoretical one.

Fig.1a shows the effect of $\mathrm{Cu}$ content on the relative density of $\mathrm{W}-\mathrm{Cu}$ composites. The relative density of the tungstencopper composites under pressure of $100 \mathrm{MPa}$ and sintering temperature of $1250{ }^{\circ} \mathrm{C}$ for 120 min fluctuate between 80 and $95 \%$. It can be clearly seen that the relative density of $\mathrm{W}-\mathrm{Cu}$ composites increases with increasing $\mathrm{Cu}$ content from 10 to $25 \mathrm{wt} \%$. We can also see that there is no significant change in the relative density when increasing the $\mathrm{Cu}$ content from 25 to $30 \mathrm{wt} \%$.

In the infiltration method, the porous compacted powder of tungsten as matrix is prepared and placed under $\mathrm{Cu}$ compacted powder. When the temperature reaches the melting point of $\mathrm{Cu}$, the molten $\mathrm{Cu}$ will fill the pores of $\mathrm{W}$ by the action of capillary forces.

However, when the amount of infiltrated $\mathrm{Cu}$ increases, the number of pores decreases, and the density of the composite should automatically increase. But if we continue to increase the amount of copper above $25 \mathrm{wt} \%$, most of pores are already filled and the density of the composites does not change much. Fig.1b shows the hardness of $\mathrm{W}-\mathrm{Cu}$ composites as a function of $\mathrm{Cu}$ weight percentage. The hardness of tungsten copper composites increases with increasing $\mathrm{Cu}$ content infiltrated in the $\mathrm{W}$ matrix. Therefore, the increase in hardness is due to the increase in melted $\mathrm{Cu}$ content in the $\mathrm{W}$ matrix, which fills almost all pores between the $\mathrm{W}$ particles and reduces the porosity in the $\mathrm{W}-\mathrm{Cu}$ composite.
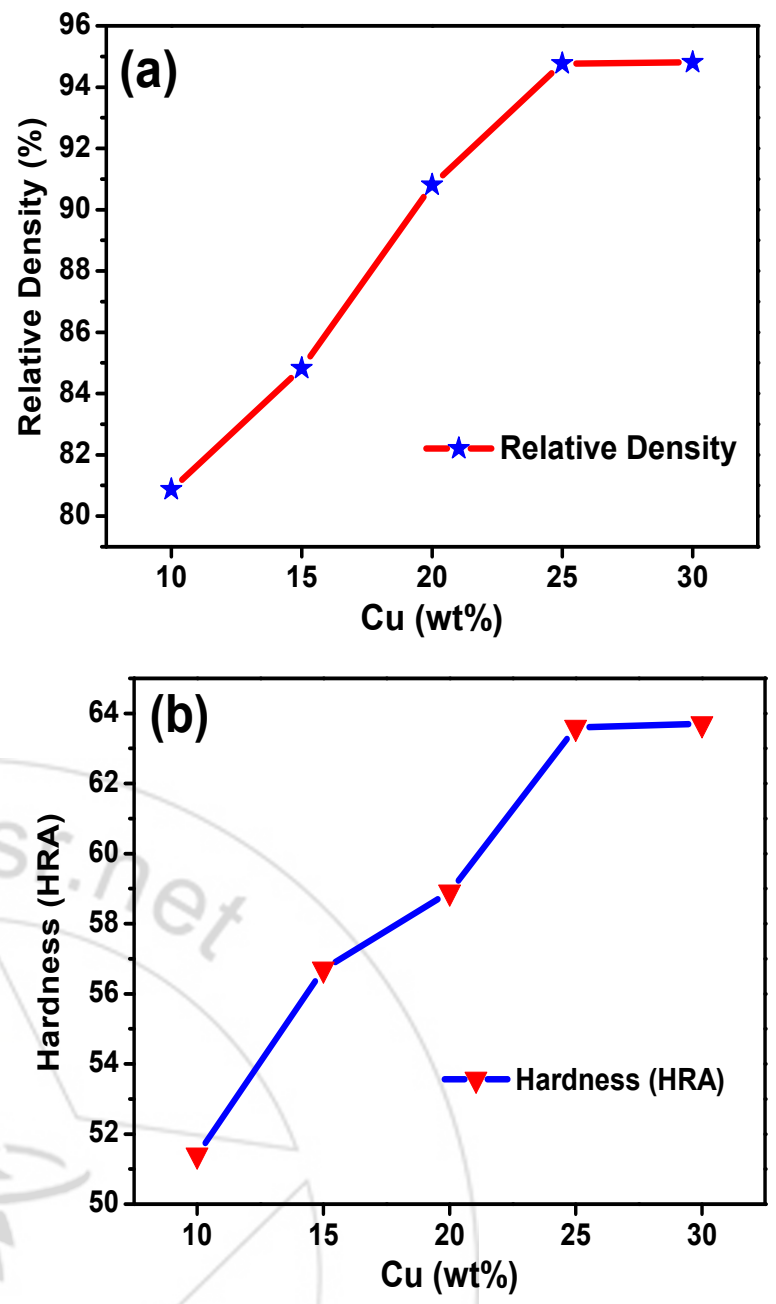

Figure 1: Effect of $\mathrm{Cu}$ content on relative sintered density and hardness of $\mathrm{W}-\mathrm{Cu}$ composites (a), (b) respectively

3.2 Effect of $\mathrm{Ni}$ addition on relative sintered density and hardness of $\mathrm{W}-\mathrm{Cu}$ composites

Figure 2 shows the effect of $\mathrm{Ni}$ addition of the $\mathrm{W}$ matrix on the relative density and hardness of $\mathrm{W}-\mathrm{Cu}$ composites, for each $\mathrm{Cu} w \mathrm{t} \%$, the relative density and hardness increase with increasing $\mathrm{Ni}$ content from 1 to $5 \mathrm{wt} \%$.

However if we continue to increase the $\mathrm{Ni}$ content from 5 to $6 \mathrm{wt} \%$, the relative density and hardness of the composites does not significantly changed, so we can conclude that the addition of $5 \mathrm{wt} \% \mathrm{Ni}$ is the optimum. During the heating up, each $\mathrm{Ni}$ particle diffuses into the grain boundaries and between the $\mathrm{W}$ particles to activate the $\mathrm{W}$ matrix. So the addition of Ni particles improves the distribution of melted $\mathrm{Cu}$ in the $\mathrm{W}$ matrix forming a dense composite. Consequently, that's lead to improve both relative density and hardness of $\mathrm{W}-\mathrm{Cu}$ composites. 


\section{International Journal of Science and Research (IJSR) \\ ISSN (Online): 2319-7064}

Index Copernicus Value (2013): 6.14 | Impact Factor (2015): 6.391
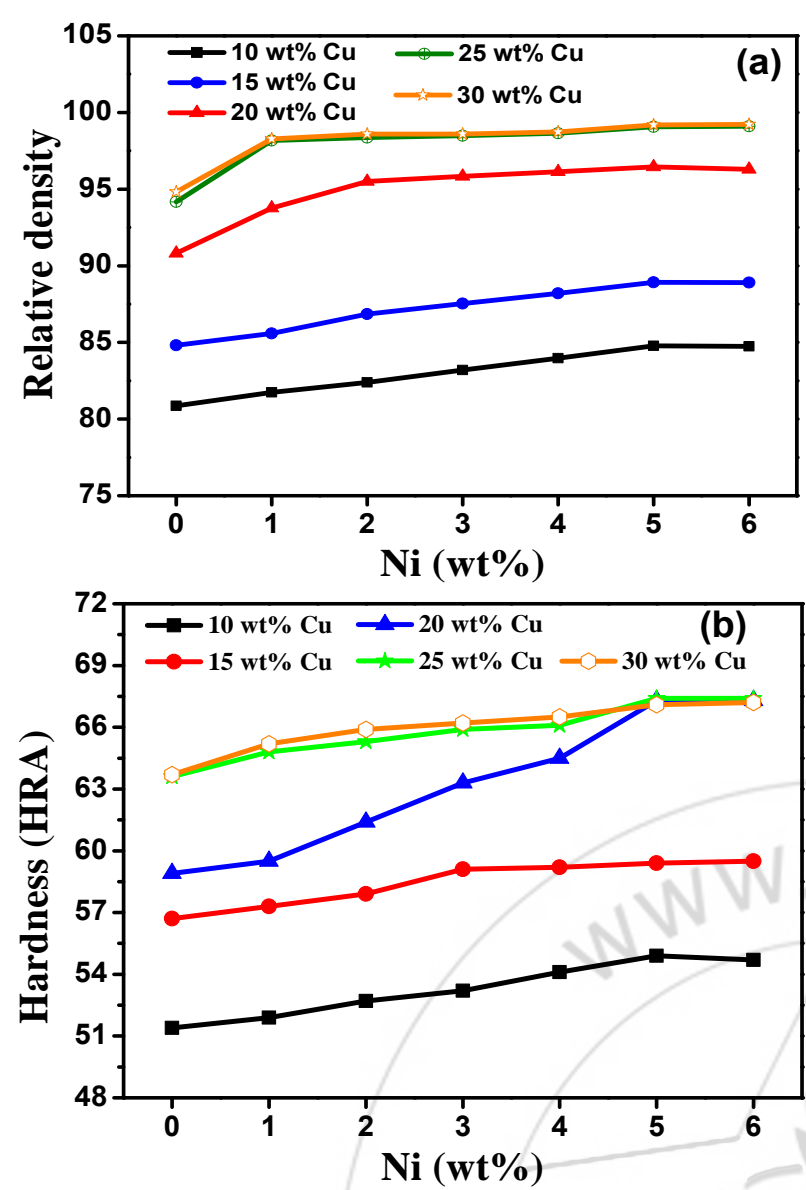

Figure 2: Effect of Ni content on relative sintered density and hardness of $\mathrm{W}-\mathrm{Cu}$ composites (a), (b) respectively.
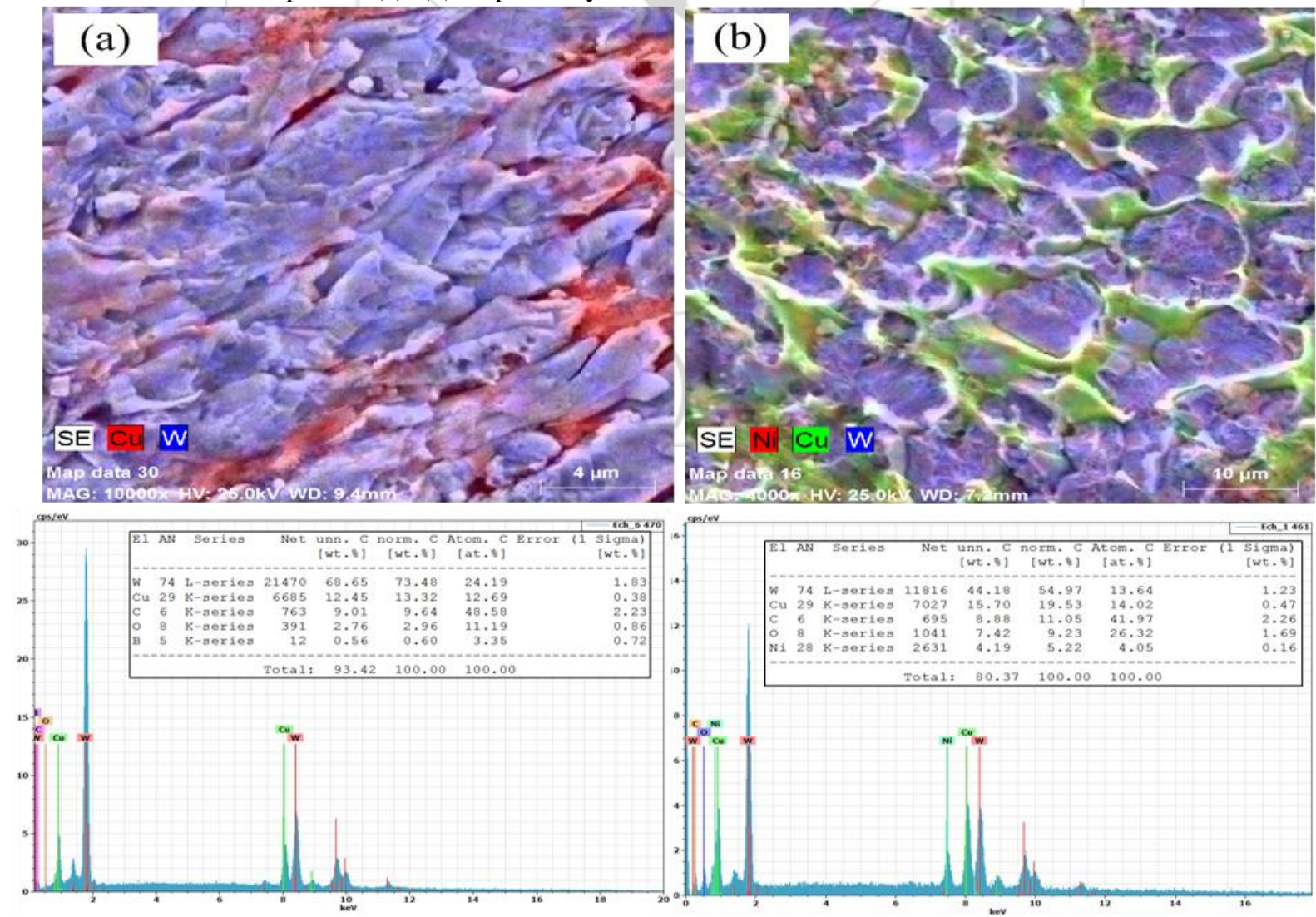

Figure 3: SEM and EDX/ cartography micrographs of $\mathrm{W}-25 \mathrm{wt} \% \mathrm{Cu}$ without/with addition of $5 \mathrm{wt} \% \mathrm{Ni}$ (a), (b) respectively.

\subsection{Effect of nickel addition on the microstructure of $W$ - $\mathrm{Cu}$ composites}

Figure 3 shows the microstructure of the infiltrated compact; we used cartography to distinguish the different phases.

In Fig.3a two phases were observed the bleu one is $\mathrm{W}$ and the red is $\mathrm{Cu}$. As we can see, a dense copper-tungsten composite was formed, but the $\mathrm{Cu}$ particles are not well distributed and relatively irregularly shaped in the matrix of W. However in Fig.3b we have three phases W (bleu), $\mathrm{Cu}$ (green), Ni (red) with smaller tungsten grains and better distribution of $\mathrm{Cu}$ in $\mathrm{W}$ matrix as a consequence of $\mathrm{Ni}$ addition giving by the fact an improvement of the wetting and adhesion of copper-tungsten and facilitate the obtaining of nonporous composite which makes uniform distribution of copper-tungsten composites. Figure 4 shows SEM and EDX cartography of (W-Ni)-Cu composite with different contents of Copper. Fig.4 (a) shows the morphology of our composite with infiltration of $10 \mathrm{wt} \% \mathrm{Cu}$, we can effectively see pores and bigger grain of tungsten, so we can assume that the amount of infiltrated $\mathrm{Cu}$ is insufficient that is why in Fig.4 (b) and 4 (c) where we added 15 and 20 wt\% shows less internal pores, so the pores decrease with increasing the amount of infiltrated $\mathrm{Cu}$. The microstructure of (W$5 w t \% \mathrm{Ni})-25 \mathrm{wt} \% \mathrm{Cu}$ illustrated in Fig.4 (d) shows a very dense composite and uniform dispersion of $\mathrm{Cu}$ in the $\mathrm{W}$ matrix with smaller grain of tungsten if we compare to the other composite, as a result from the combination of the microstructural observations and the density test result, it can be concluded that the addition of $25 \mathrm{wt} \%$ of $\mathrm{Cu}$ is the best in order to get a dense and homogenous (W-Ni)-Cu composite

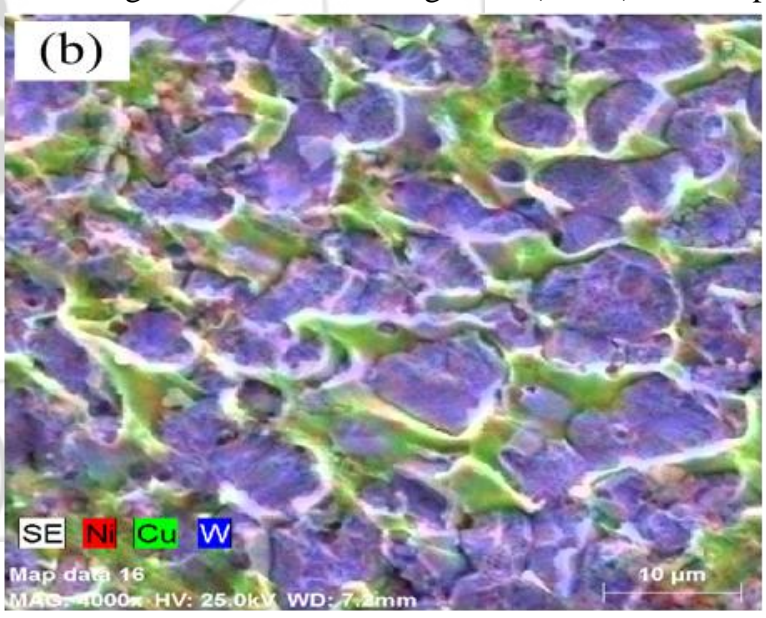




\section{International Journal of Science and Research (IJSR) \\ ISSN (Online): 2319-7064}

Index Copernicus Value (2013): 6.14 | Impact Factor (2015): 6.391

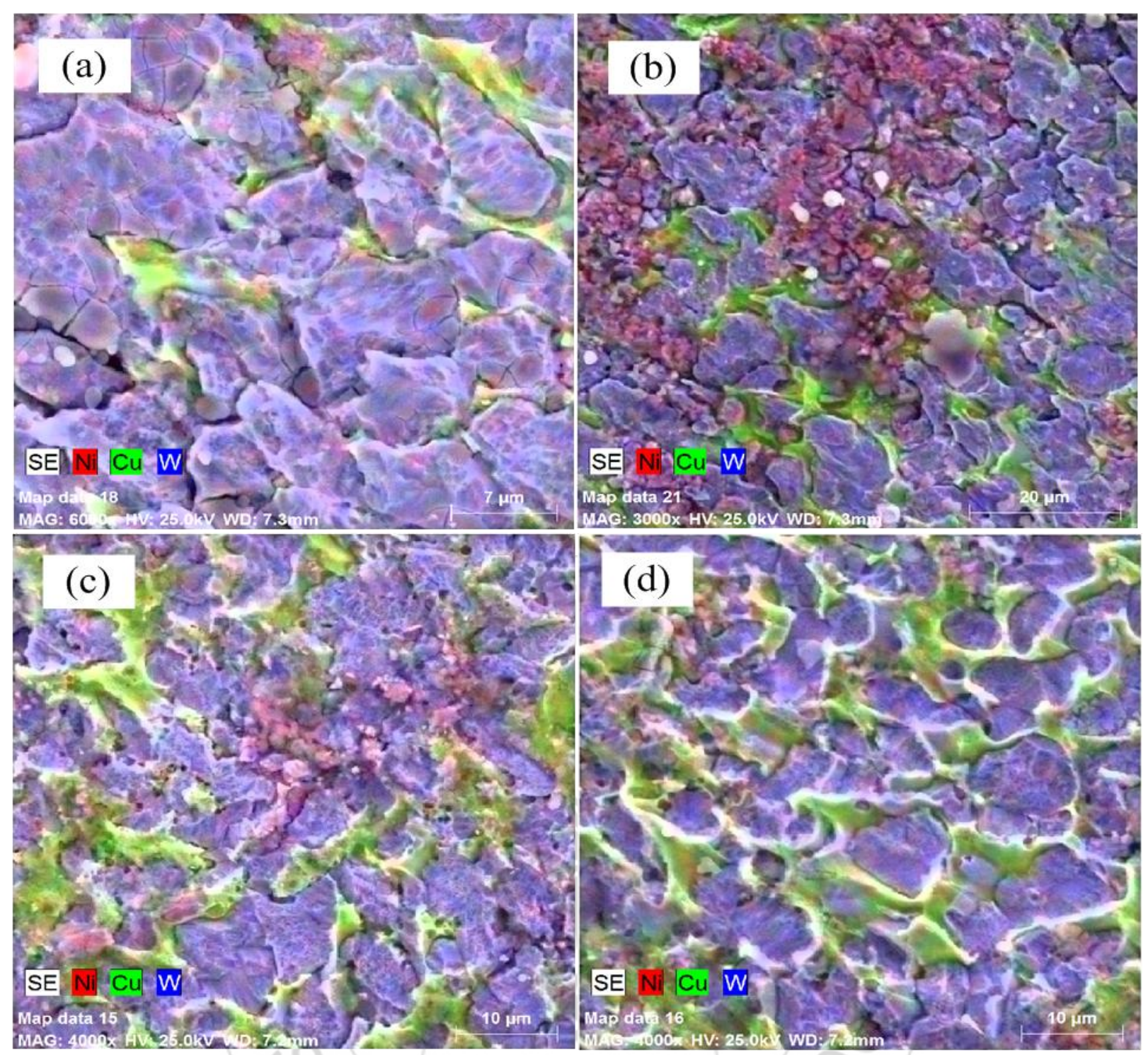

Figure 4: SEM and EDX/ cartography micrographs of the composite W-Cu-5wt \% Ni with different contents of $\mathrm{Cu}$ : (a) $10 \mathrm{wt} \%$ $\mathrm{Cu}$, (b) $15 \mathrm{wt} \% \mathrm{Cu}$, (c) $20 \mathrm{wt} \% \mathrm{Cu}$, (d) $25 \mathrm{wt} \% \mathrm{Cu}$

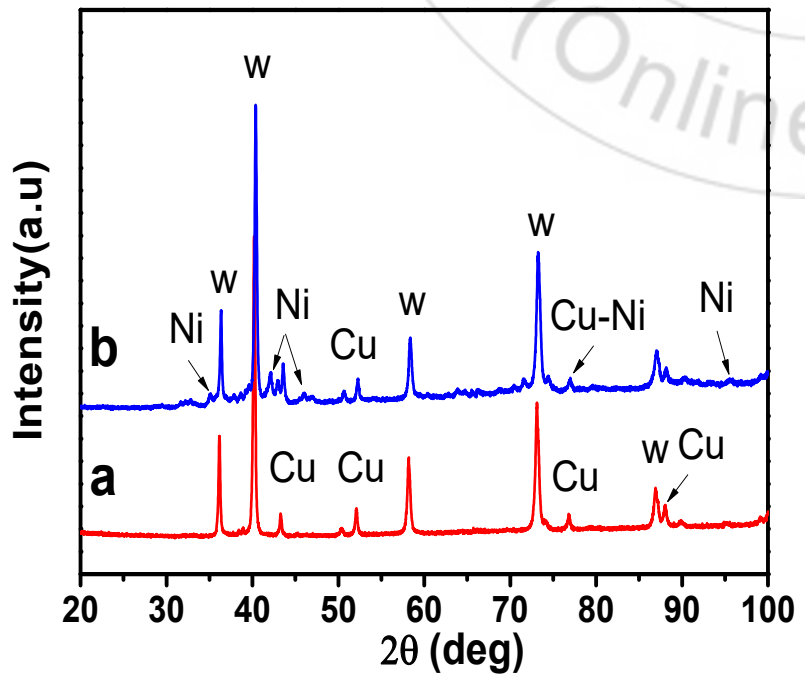

Figure 5: XRD patterns of the produced composites after infiltration process; (a): $75 \mathrm{wt} \%(\mathrm{~W}+0 \mathrm{wt} \% \mathrm{Ni})-25 \mathrm{wt} \% \mathrm{Cu}$,

(b): $75 \mathrm{wt} \%(\mathrm{~W}+5 \mathrm{wt} \% \mathrm{Ni})-25 \mathrm{wt} \% \mathrm{Cu}$.

X-ray diffraction patterns of the infiltrated sample $(25 \mathrm{wt} \% \mathrm{Cu})$ without and with $5 \mathrm{wt} \% \mathrm{Ni}$ addition are shown in
Figure 5. From Fig.5a, two kinds of peaks are observed (W and $\mathrm{Cu}$ ).

The relative intensity of tungsten peaks is considerably higher than those of copper which is in concordance with our study (W substrate infiltrated by $\mathrm{Cu}$ ).

Fig.5b shows the apparition of new small intensity peaks of nickel in addition to tungsten and copper peaks. The tungsten peaks relative intensity is remarkably higher than copper peaks intensity which exceeds nickel peaks intensity.

The formation of $\mathrm{Cu}-\mathrm{Ni}$ intermetallic compound can be confirmed by the existence of $\mathrm{Cu}-\mathrm{Ni}$ peaks.

\section{Conclusion}

In this work, (W-Ni)-Cu composites via infiltration process were successfully elaborated. The effect of $\mathrm{Cu}$ content as infiltrated part on the density and hardness of $\mathrm{W}-\mathrm{Cu}$ composites was investigated.

\section{Volume 5 Issue 5, May 2016}




\section{International Journal of Science and Research (IJSR) \\ ISSN (Online): 2319-7064 \\ Index Copernicus Value (2013): 6.14 | Impact Factor (2015): 6.391}

The highest relative density and hardness were found at 25 $\mathrm{Wt} \% \mathrm{Cu}$ without addition of $\mathrm{Ni}$. The most interesting result was found at $5 \mathrm{wt} \% \mathrm{Ni}$ addition to $\mathrm{W}-\mathrm{Cu}$ composites, where it increases both relative density and hardness by $5 \%$ and $6 \%$ respectively, compared to the same weight percent of $\mathrm{W}-\mathrm{Cu}$ composite without addition of Ni.

Morphological investigations revealed that the presence of $\mathrm{Ni}$ as activator helps the wetting of copper in tungsten and improves the infiltration efficiency to get uniform distribution of $\mathrm{Cu}$ in $\mathrm{W}$ matrix.

This uniform distribution of melted $\mathrm{Cu}$ binder provided a good interaction between particles of $\mathrm{W}$ matrix composites.

The optimum $5 \mathrm{wt} \% \mathrm{Ni}$ activator and $25 \mathrm{wt} \% \mathrm{Cu}$ infiltrated fills almost all pores between $\mathrm{W}$ particles.

Additionally, the existence in of $\mathrm{Ni}$ in the prepared composites was confirmed using the EDX and XRD analysis.

\section{References}

[1] Y. Song, Q. Li, J. Li, G. He, Y. Chen, and H.S. Kim. "Fabrication of $\mathrm{W}-\mathrm{Cu}$ alloy via combustion Synthesis Infiltration under an Ultra-Gravity Field," Met. Mater. Int., Vol. 20, No. 6, (2014), pp. 1145-1150.

[2] B. Gowon, K.S. Mohammed, S.B. B. Jamaluddin, and J. Hussain, "Densification of W-brass Composites by Infiltration, International Journal of Science and Research," 2015, vol.4, pp. 72-75.

[3] L. Shu-dong, Y. Jian-hong, G. Ying-li, P. Yuan-dong, L. Li-ya, and R. Jun-ming, "Microwave sintering $\mathrm{W}-\mathrm{Cu}$ composites: Analyses of densification and microstructural homogenization, J. Alloys and Comp ,2009, 473, pp. L5-L9.

[4] M. Ardestani, H. Arabi, H. R. Rezaie, et al : Int. J. Refract. Met. Hard Mater, 2009, 27(4), 796-800.

[5] A. Upadhyaya, "Processing strategy for consolidating tungsten heavy alloys for ordnance applications," Materials Chemistry and Physics," 2001, vol. 67,pp. 101-110.

[6] N.Q. Zhao, J.J. Li, X.J. Yang, "Influence of the P/M process on the microstructure and properties of WC reinforced copper matrix composite, Journal of Materials Science," (2004), vol 39, 4829-4834.

[7] N.Q. Zhao, J.J. Li, X.J. Yang, "Influence of the P/M process on the microstructure and properties of WC reinforced copper matrix composite, Journal of Materials Science," (2004), vol 39, 4829-4834.

[8] K.V. Sebastian, "Properties of sintered and infiltrated tungsten-copper electrical contact material, International Journal of Powder Metallurgy and Powder Technology," (1981), vol 17, 297-303.

[9] J.L. Johnson, J.J. Brezovsky, and R.M. German, "Effect of liquid content on distortion and rearrangement densification of liquid-phase-sintered W-Cu," Metall. Mater. Trans. A, 2005, vol.36, pp.1557-1565.

[10] J. Lezanski, W. Rutkowski, "Infiltration of a liquid in sintered tungsten - 3 stages of infiltration, Powder Metallurgy International,” (1987), vol 19, 29-31.
[11] R. Mitteau, J.M. Missiaen, P. Brustolin, O. Ozer, A. Durocher, C. Ruset, C.P. Lungu, X. Courtois, C. Dominicy, H. Maier, C. Grisolia, G. Piazza, P. Chappuis, "Recent developments toward the use of tungsten as armour material in plasma facing components," Fusion Eng. Des, 2007, vol 82, pp 1700 1705.

[12] M. Rosinski, E. Fortuna, A. Michalski, Z. Pakiela, K. J. Kurzydlowski "W/Cu composites produced by pulse plasma sintering technique (PPS)," Fusion and Engineering Design, Special Edition of the Elsevier journal, 82 (2007) 2621-2626.

[13] D. Zhang, Q. Cai, J. Liu, J. He, and R. Li "Microstructural evolvement and formation of selective laser melting W-Ni-Cu composite powder," Int J Adv Manuf Technol, 2013, vol. 67, pp. 2233- 2242.

[14] A. Ghaderi Hamidi, H. Arabi, S. Rastegari, "Tungsten-copper composite production by activated sintering and infiltration," Int. Journal of Refractory Metals \& Hard Materials, 2011, vol.29, pp.538-541. 